\title{
Atti Sociali
}

\section{SOCIETA' ENTOMOLOGICA ITALIANA}

\section{BILANCIO CONSUNTIVO 2018}

\section{STATO PATRIMONIALE AL 31.12.2018}

Patrimonio Sociale

Immobile Sede Biblioteca Sociale (valore catastale riv.)

Fondo riserva

Mobili \& Attrezzi (pro memoria)

Biblioteca (pro memoria)
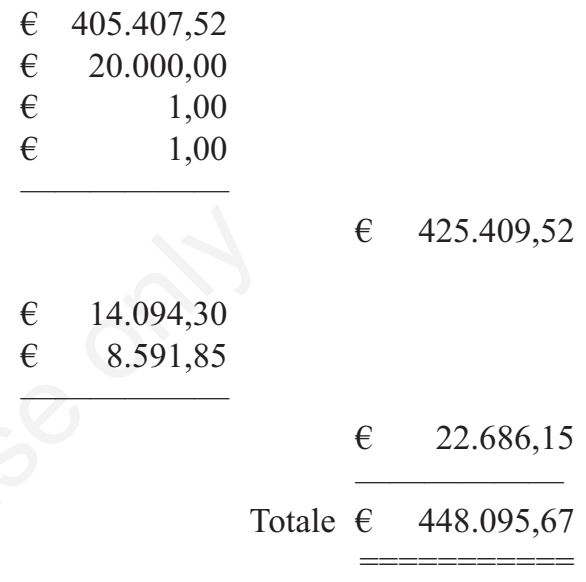

LIQUIDITÀ AL 31.12.2018

Conto corrente bancario

Conto corrente postale
$€ \quad 14.094,30$

$8.591,85$

\section{RENDICONTO DI CASSA AL 31.12.2018}

INTROITI

1. Liquidità al 31.12.2017

2. Quote sociali (importi netti)

3. Contributo 5\% ex-IRPEF

4. Contributo ministeriale

5. Rimborsi

ESBORSI

6. Conto economico

7. Costo pubblicazioni sociali (stampa, confezione \& spedizione)

LIQUIDITÀ FINALE AL 31.12.2018 (come da stato patrimoniale)

8. Accantonamento a fronte rischi

RATEI PASSIVI AL 31.12.2018

Spese pubblicazione (a calcolo)

Stampa, confezione e spedizione

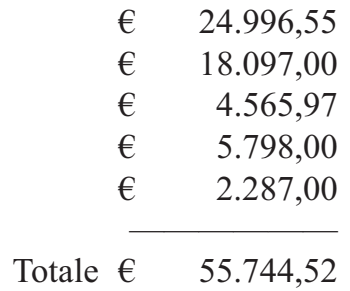

$€ \quad 12.455,98$

$€ \quad 20.602,39$
$€ \quad 1.000,00$

Totale $€ \quad 1.000,00$

Disavanzo al 31.12.2018

$€ \quad 313,85$


III. DIMOSTRAZIONE DEL CONTO ECONOMICO 2018

6.1 - Gestione ordinaria Sede Sociale

6.2 - Biblioteca Sociale

6.3 - Fondo minute spese Segreteria

6.4 - Fondo minute spese Biblioteca

6.5 - Fondo minute spese Amministrazione

6.6 - Postali e bancarie ordinarie

6.7 - Spese spedizioni

6.8 - Assicurazioni diverse

6.9 - Imposte e tasse

$€ \quad 5.586,83$

$€ \quad 2.744,35$

$€ \quad 300,00$

$€ \quad 500,00$

$€ \quad 200,00$

$€ \quad 605,80$

$€ \quad 1.115,00$

$€ \quad 632,00$

$€ \quad 772,00$

Saldo al 31.12.2018 (come da rendiconto di cassa)

\section{BILANCIO PREVENTIVO ANNO 2019}

INTROITI

1. Quote sociali

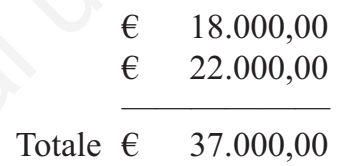

2. Utilizzo fondo di riserva

ESBORSI

3. Ratei passivi al 31.12.2018

4. Spese pubblicazione (stampa, confezione, spedizione)

5. Biblioteca sociale

6. Spese generali di gestione, incl. imposte e tasse

\begin{tabular}{rr}
$€$ & $1.000,00$ \\
$€$ & $21.000,00$ \\
$€$ & $7.000,00$ \\
$€$ & $11.000,00$ \\
\cline { 2 - 2 } Totale & \\
\hline & $40.000,00$
\end{tabular}

L'Amministratore

Il Bibliotecario

(Giulio Gardini)

(Antonio Rey)

Il Presidente SEI

(Prof. Francesco Pennacchio) 


\section{Giovanni Laffi}

Nato a Genova Sampierdarena il 6 ottobre 1942, è deceduto a Genova Pegli, dove risiedeva, il 20 dicembre 2018.

Tecnico di una grande industria genovese, si appassionò già da adulto al mondo degli insetti, iscrivendosi alla nostra Società nel 1999. Abituale frequentatore delle edizioni di Entomodena, radunò materiali appartenenti a diversi ordini; non sono note sue pubblicazioni. Alla famiglia vanno le sentite condoglianze della Società. 